\title{
Reducing pesticide level in wine by selective filtration
}

\author{
Valérie Lempereur $^{1, \text { a }}$, Celine Louaisil ${ }^{2}$, and François Davaux ${ }^{3}$ \\ ${ }^{1}$ Institut Français de la Vigne et du Vin (IFV), 210 boulevard Vermorel, CS60320, 69661 Villefranche s/Saône Cedex, \\ France \\ ${ }^{2}$ REALDYME, ZA Diepe, 28700 Garancières en Beauce, France \\ ${ }^{3}$ Institut Français de la Vigne et du Vin (IFV), V'innopole, Brame-Aïgues, BP. 22, 81310 Lisle sur Tarn, France
}

\begin{abstract}
Wine Pesticide residues, even when below grape regulatory limit, are a concern for consumers and have an impact on the export potential of wine in certain markets. A consortium of European SMEs (www.adfimax.com) has developed a product that reduces the level of mycotoxins and pesticides in wine while keeping all other wine parameter identical. The product is derived from renewable vegetable fiber. The production process includes both activation and micronisation. The usage recommendation is to substitute only the pre-coat, typically perlite, by the product at 1 or $1.5 \mathrm{~kg} \cdot \mathrm{m}^{-2}$ without changing the other layer (body feed) typically kieselguhr. This paper describes the results of numerous industrial trials that were performed in France, Luxemburg, Germany and Spain. The impact of the product on the wine oenological characteristics was evaluated for different wine (white, red and rosé) in different countries and for different grape variety (including Cabernet sauvignon, Merlot and Gamay). Results showed a reduction of the test wine pesticide level of 50\% to $60 \%$ for all pesticides compared to the blank. Level of pesticide analyzed in the cake where extremely high at a level of a 1,000 times greater than the filtered wine showing the ability of the product to selectively capture the pesticides molecules.
\end{abstract}

\section{Introduction}

The technology developed by the consortium of European SMEs is based on a activated vegetal fibre (AVF) that adsorbs pesticides and other unwanted contaminants such as mycotoxins while not impacting the other characteristics of wine such as color and taste. This activated vegetal fibre (AVF) can be integrated into a filter sheet [1] or directly used as a filter adjuvant [2].

In the present study we have investigated the ability to use AVF as a substitute of a pre-coat product such as kieselguhr in a diatomaceous earth (DE) filtration. Tests have been done on wine on different scales: lab, pilot and industrial scales. Under experimental authorizations, industrials filtrations were performed in France, Luxembourg, Germany and Spain. Each filtration was benchmarked against a normal kieselguhr filtration (blank). We report in this study our evaluation on the ability to use AVF as a filter adjuvant, on the efficiency of AVF to bind pesticides and on the impact of AVF on the oenological and organoleptic parameters of the wine.

\section{Materials and methods}

\subsection{Experimental protocol}

The same filtration set up with continuous deposit was used for all industrial filtrations. The industrial filtrations

\footnotetext{
${ }^{a}$ Corresponding author: valerie.lempereur@vignevin.com
}

were performed with a $40 * 40 \mathrm{DE}$ filter of approximately $0.86 \mathrm{~m}^{2}$. All industrial filtrations were monitored by IFV. The trial design included a blank. The only difference between the blank and the test wine was the substitution of the normal pre-coat by AVF (see Table 1).

Table 1. Filtration parameters.

\begin{tabular}{|l|c|c|}
\hline & Blank & Test product \\
\hline Filter & $\begin{array}{l}\text { Press filter } \\
40^{*} 40 \mathrm{~cm}\end{array}$ & $\begin{array}{l}\text { Press filter } \\
40^{*} 40 \mathrm{~cm}\end{array}$ \\
\hline Surface filter $\left(\mathrm{m}^{2}\right)$ & 0.864 & 0.864 \\
\hline Precoat 1 & Kieselguhr & Kieselguhr \\
\hline Precoat 1 (quantity kg/m $\left.{ }^{2}\right)$ & 0.5 & 0.1 \\
\hline Precoat 2 & Kieselguhr & AVF \\
\hline Precoat 2 (quantity kg/m $\left.{ }^{2}\right)$ & 0.5 & 1.5 \\
\hline Body feed & Kieselguhr & Kieselguhr \\
\hline Body feed (quantity g/hL) & 70 & 70 \\
\hline Filtration flow rate $\left(\mathrm{hL} / \mathrm{h} / \mathrm{m}^{2}\right)$ & 10 & 10 \\
\hline
\end{tabular}

\subsection{Tested wines characteristics}

For each trial a commercial wine representative of the market was filtered. Filtrations were done in different countries: France, Germany, Luxembourg and Spain. Trials done in France were performed under the experimental authorization given by the DGCCRF.

This is an Open Access article distributed under the terms of the Creative Commons Attribution License 4.0, which permits unrestricted use, distribution, and reproduction in any medium, provided the original work is properly cited. 
Table 2. Description of the trials.

\begin{tabular}{|l|l|l|l|l|l|l|l|}
\hline Ref trial & 3013 & 3014 & 3017 & 3018 & 3019 & 3021 & 3022 \\
\hline $\begin{array}{l}\text { Type of } \\
\text { wine }\end{array}$ & White & Red & White & Red & Rosé & Red & Red \\
\hline Vintage & 2013 & 2013 & 2013 & 2013 & 2013 & 2013 & 2012 \\
\hline $\begin{array}{l}\text { Total } \\
\text { Volume } \\
\text { (hL) }\end{array}$ & 46 & 50 & 25 & 19 & 30 & 14 & 15 \\
\hline
\end{tabular}

\subsection{Tested adjuvants characteristics}

Commercial kieselguhrs were obtained from Laffort and Eaton and were chosen according to the wine turbidity. The chemical composition of AVF used in these industrial trials is typical of a vegetal fiber with component such as hemicellulose, cellulose, lignin, proteins and lipids. AVF is a black-fine powder insoluble in water and in wine. The particle size distribution of AVF is between 5 and $150 \mu \mathrm{m}$, $90 \%$ are below $50 \mu \mathrm{m}$. The filtration specifications of AVF are a wet density of $900 \mathrm{~g} / \mathrm{L}$ and a permeability of 0.09 Darcy. All batches of AVF used in these industrials filtration were checked following a quality plan, especially to validate that AVF is free from undesirable components (pesticides residues, pathogens, dioxins ....).

The AVF received the regulatory approval for experimental usage in France by DGCCRF and the FDA approval in Germany for the rest of the world.

\subsection{Analysis}

\subsubsection{Filtration efficiency and efficacy}

The filtration efficiency is achieved by measuring the wine turbidity. The filtration efficacy is achieved by measuring the flow rate and pressure increase by an automatic data logger system. The kinetic filtration evolution determinates the level of filter clogging.

\subsubsection{Binding capacity}

Multi-residues analysis is realized on the initial wine before treatment, then on the same wine after treatment with product and blank test. The sample is extracted using the Quick, Easy, Cheap, Effective, Rugged and Safe (QuEChERS) method. $10 \mathrm{~mL}$ of wine are extracted using acetonitrile followed by liquid-liquid partitioning induced by adding buffering salts (magnesium sulphate, sodium chloride, disodium hydrogen citrate sesquihydrate, trisodium citrate dehydrate). After centrifugation, extracts are transferred into vials for UPLC/MS/MS analysis (Waters Acquity UPLC connected to a Waters Acquity TQD tandem mass spectrometer). The quantification is made by external calibration. Limits of Quantification (LQ) and Limits of detection (LD) are 1 and $0.5 \mu \mathrm{g} / \mathrm{L}$. Multipesticides residues analyses (UPLC/MS/MS analysis) are realized on the filter cake too. After filtration, the cake is sampled with a die of $10 \mathrm{~cm}$ diameter. The sample consists of kieselguhr and AVF. Four samples are taken into each cake. The results are expressed in $\mu \mathrm{g} / \mathrm{kg}$ of wet cake.

The pesticides residues analyses were performed at IFV in France [3].

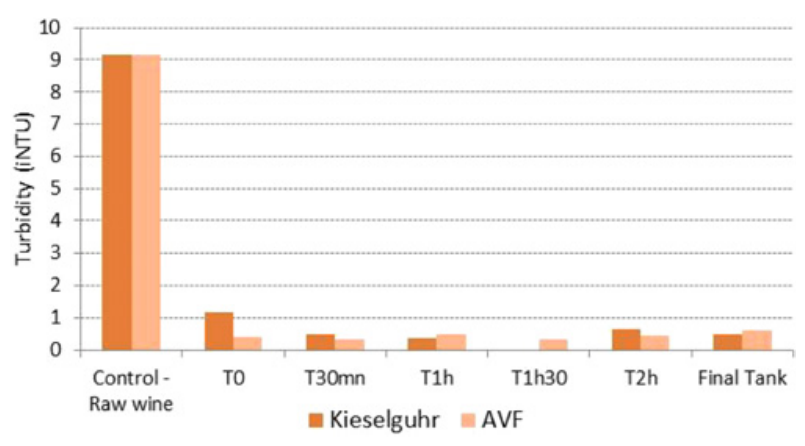

Figure 1. Wine turbidity during the filtration (rosé wine 3019).

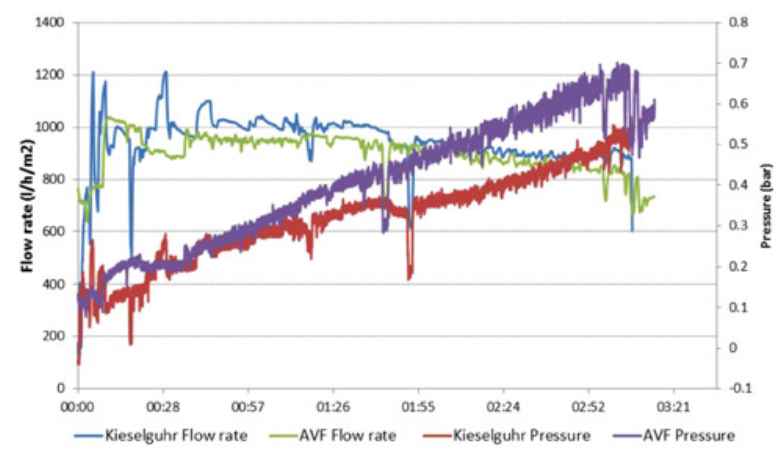

Figure 2. Pressure and flow rate during the filtration (red wine 3014).

\subsubsection{Oenological analysis}

Filtered wine was bottled and analyzed for oenological classical parameters: color intensity at 420,520 and $620 \mathrm{~nm}$, anthocyanin, polyphenols, Lab measurement, malic and lactic acid, tartaric acid, $\mathrm{SO}_{2}$ content, $\mathrm{pH}$. The color difference between two samples is expressed in Delta E.

$$
\Delta \mathrm{E}_{\mathrm{ab}}^{*}=[(\Delta \mathrm{L} 2)+(\Delta \mathrm{a} 2)+(\Delta \mathrm{b} 2)]^{1 / 2}
$$

A difference of color lower than 5 units involves that two samples are not perceived different by the eye [4].

Ester analysis was made by GC-MS.

\subsubsection{Sensory analysis}

The sensory test impact was performed by a triangular test in black glasses. All tests samples were compared to the reference filtration (blank). The results are shown with a significance of $5 \%$. The sensory test impact was performed at IFV in France.

\section{Results and discussion}

\subsection{Filtration efficacy and efficiency}

In all demonstration trials, filtration with AVF is similar to blank filtration. The Figs. 1 and 2 shows that the reduction of turbidity is similar to the turbidity obtained with the blank filtration and that no clogging of the filter has been observed. These results are typical of the filtrations. 
Table 3. Pesticides level in wine for each trial.

\begin{tabular}{|c|c|c|c|c|c|}
\cline { 2 - 6 } \multicolumn{1}{c|}{} & $\begin{array}{l}\text { Before } \\
\text { filtration }\end{array}$ & \multicolumn{2}{|c|}{$\begin{array}{l}\text { After kieselguhr } \\
\text { filtration }\end{array}$} & \multicolumn{2}{c|}{ After AVF filtration } \\
\hline Trial & $\begin{array}{l}\text { Total } \\
\text { pesticides } \\
(\mu \mathrm{g} / \mathrm{l})\end{array}$ & $\begin{array}{l}\text { Total } \\
\text { pesticides } \\
(\mu \mathrm{g} / \mathrm{L})\end{array}$ & $\begin{array}{l}\text { reduction } \\
(\%)\end{array}$ & $\begin{array}{l}\text { Total } \\
\text { pesticides } \\
(\mu \mathrm{g} / \mathrm{L})\end{array}$ & $\begin{array}{l}\text { reduction } \\
(\%)\end{array}$ \\
\hline 3013 & 12.2 & 11.3 & 7.3 & 4.2 & 65 \\
\hline 3014 & 14.4 & 14.8 & 0 & 6.6 & 54 \\
\hline 3017 & 62.9 & 63.2 & 0 & 25.1 & 60 \\
\hline 3018 & 60.2 & 58.7 & 2.5 & 26.8 & 55 \\
\hline 3019 & 1.4 & 1.4 & 0 & 1 & 28 \\
\hline 3021 & 62.6 & 59.7 & 5 & 35.9 & 40 \\
\hline 3022 & 53.9 & 53.8 & 0 & 33.4 & 33 \\
\hline
\end{tabular}

\subsection{Binding capacity}

\subsubsection{Measurement in wine}

The adsorption properties evaluation of the AVF was based on the pesticides residues analysis of the filtered wine of each trial. All filtered and un-filtered wines were analyzed by the same method in the same location. Pesticides residues analyses have revealed that all selected wines contained residues.

As compared with the blank filtered wines, Table 3 confirms that AVF could significantly reduce the pesticides residues in wine by $55 \%$ to $65 \%$ whatever the type of the wine (red or white) or the initial concentration of pesticides residues. Both in red and white wine the pesticide overall reduction was above $50 \%$ with sometime very different original wine pesticide concentration. In the red trial 3018 we had a $55 \%$ overall reduction with a $60.2 \mathrm{ppb}$ original contamination while we had $54 \%$ reduction in trial 3014 with $14.4 \mathrm{ppb}$ original pesticide concentration. Table 4 shows the cartography of molecules found in the wines. Three categories of pesticides reduction are made: below $50 \%$, between 50 to $80 \%$ and more than $80 \%$ (see Table 4). The global pesticides reduction was $55 \%$ in the wine.

However it was observed that the binding capacity of AVF was lower for substances such as Fenhexamide, Iprovalicarb and Metalaxyl-M. Those three molecules are qualified low adsorbed molecules.

The other pesticides residues are qualified high adsorbed molecules. Figures 3 and 4 confirm that AVF adsorbed high adsorbed molecules. The low adsorbed molecule contained in the wine of the trial 3021 is composed by $36 \mu \mathrm{g} / \mathrm{L}$ of Metalaxyl-M. After AVF filtration, the wine contains $32.6 \mu \mathrm{g} / \mathrm{L}$ of Metalaxyl-M.

The Table 5 shows the pesticides reduction observed in wines on the low adsorbed molecules and on the high adsorbed molecules. After AVF filtration, the reduction of high adsorbed molecules fluctuates from 55 to $88 \%$.

\subsubsection{Measurement in filter cake}

The filter cake was extracted to determine how much pesticide was adsorbed. All pesticide that were removed from the wine were identified in the cake, confirming that binding takes place even for substances with less reduction, such as Fenhexamide. The level of pesticide in the cake of one trial is showed in Table 6.
Table 4. Cartography of pesticides residues.

\begin{tabular}{|l|c|c|c|c|}
\hline Pesticides & $\begin{array}{c}\text { Number of trials } \\
\text { where the } \\
\text { rolecule detected } \\
\text { / number of trials }\end{array}$ & $\begin{array}{l}\text { Number of case where } \\
\text { the of reduction was } \\
\text { between : }\end{array}$ \\
\cline { 3 - 5 } & & $80-100 \%$ & $50-80 \%$ & $0-50 \%$ \\
\hline Azoxystrobine & $4 / 7$ & 2 & 2 & \\
\hline Boscalid & $6 / 7$ & 4 & 2 & \\
\hline Benalaxyl & $1 / 7$ & 1 & & \\
\hline Carbendazime & $1 / 7$ & & & 1 \\
\hline Cyprodinil & $4 / 7$ & 4 & & \\
\hline Dimetomorphe & $6 / 7$ & 3 & 2 & 1 \\
\hline Fenhexamide & $4 / 7$ & & & 4 \\
\hline Fludioxinil & $3 / 7$ & 3 & & \\
\hline Fluopicolide & $2 / 7$ & & 2 & \\
\hline Iprodione & $1 / 7$ & 1 & & \\
\hline Iprovalicarb & $3 / 7$ & & & 3 \\
\hline Mandipropamid & $3 / 7$ & 2 & 1 & \\
\hline Metalaxyl-M & $3 / 7$ & & & 3 \\
\hline Metrafenone & $2 / 7$ & 2 & & \\
\hline Myclobutanil & $3 / 7$ & 1 & 2 & \\
\hline Pyrimethanil & $4 / 7$ & & 4 & \\
\hline Spiroxamine & $1 / 7$ & & 1 & \\
\hline Tebuconazole & $2 / 7$ & 1 & 1 & \\
\hline Tebufenozide & $1 / 7$ & & 1 & \\
\hline Triadimenol & $1 / 7$ & & & 1 \\
\hline
\end{tabular}

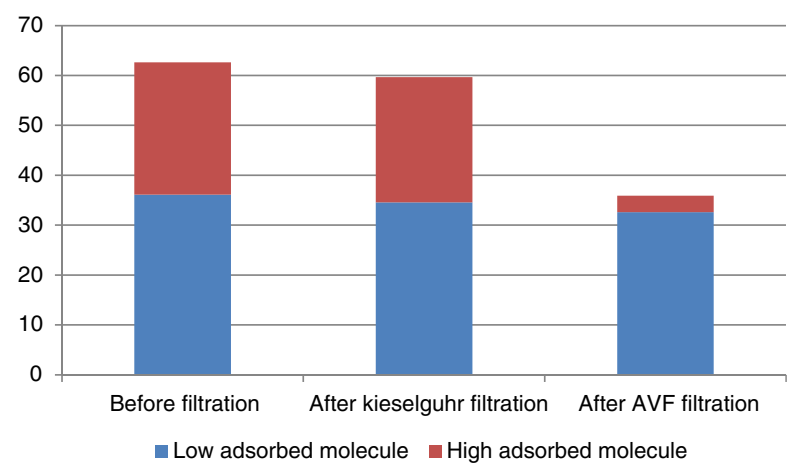

Figure 3. Filtration trial on wine containing high level of low adsorbed molecules (trial 3021).

The difference between the theoretical concentration and the observed concentration is justified by the sampling. Indeed we only sampled a fraction of the filter surface of 
Table 5. Pesticides level in wine for each trial.

\begin{tabular}{|c|c|c|c|c|c|c|}
\hline & \multicolumn{2}{|c|}{ Before filtration } & \multicolumn{4}{|c|}{ After AVF filtration } \\
\hline Trial & $\begin{array}{l}\text { Total of } \\
\text { LAM } \\
(\mu \mathrm{g} / \mathrm{L})\end{array}$ & $\begin{array}{l}\text { Total of } \\
\text { HAM } \\
(\mu \mathrm{g} / \mathrm{L})\end{array}$ & $\begin{array}{l}\text { Total of } \\
\text { LAM } \\
(\mu \mathrm{g} / \mathrm{L})\end{array}$ & $\begin{array}{l}\text { Total of } \\
\text { HAM } \\
(\mu \mathrm{g} / \mathrm{L})\end{array}$ & $\begin{array}{l}\text { Reduction } \\
\text { of LAM } \\
(\%)\end{array}$ & $\begin{array}{l}\text { Reduction } \\
\text { of HAM } \\
(\%)\end{array}$ \\
\hline 3013 & 3.8 & 8.4 & 2.5 & 1.7 & 34 & 80 \\
\hline 3014 & 1.0 & 13.4 & 0.6 & 6 & 40 & 55 \\
\hline 3017 & 32.6 & 30.3 & 19 & 6.1 & 42 & 80 \\
\hline 3018 & 22.6 & 37.6 & 17 & 9.8 & 25 & 74 \\
\hline 3019 & 1.4 & $<\mathrm{LQ}$ & 1 & $<\mathrm{LQ}$ & 29 & - \\
\hline 3021 & 36.1 & 26.5 & 32.6 & 3.3 & 10 & 88 \\
\hline 3022 & 28.7 & 25.2 & 25.2 & 8.2 & 12 & 67 \\
\hline
\end{tabular}

LAM: low adsorbed molecules - HAM: high adsorbed molecules.

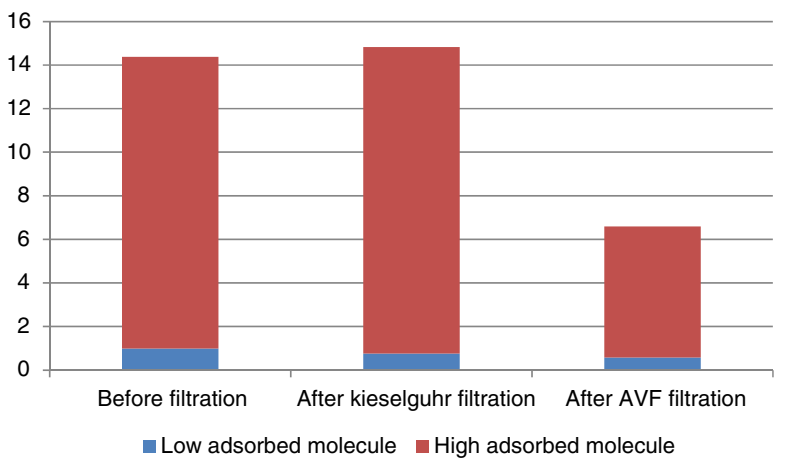

Figure 4. Filtration trial on wine containing low level of low adsorbed molecules (trial 3014).

the cake. This assumes that the cake was evenly spread on the filter surface which was not the case in the experimental setting. Another hypothesis is that pesticides were not completely desorbed from the cake during the analytical extraction. The levels found in the cake thus represent the minimum levels that are present in the cake. The data are however consistent.

The surprise of the cake analysis was that some pesticides not detected in the wine were detected in the cake. In the trial 3021, a total of 17 pesticides molecules not found in the initial wine were accumulated in the cake above detection limits, with a total of $651 \mu \mathrm{g} / \mathrm{kg}$. This shows the ability of AVF to capture pesticides present at very low concentration (below detection limit).

\subsection{Oenological analysis}

The main oenological parameters were measure on filtered wine. The Table 7 recapitulates the main average values, presented by type of wine color. The AVF leads to an adsorption of the phenolic compounds of the wine. The delta $\mathrm{E}$ are below the level of 5, which is the visible level.

The color intensity was analyzed during the filtration. Wine was sampled at the output of the filter. Figure 5 shows that there is a reduction of the color intensity at the beginning of the filtration. In the final tank, no visible difference could be seen. The value of delta $E$ was 2.4.

The esters analysis shows a slight reduction of esters due to the filtration step (see Fig. 6). The aromatic profile

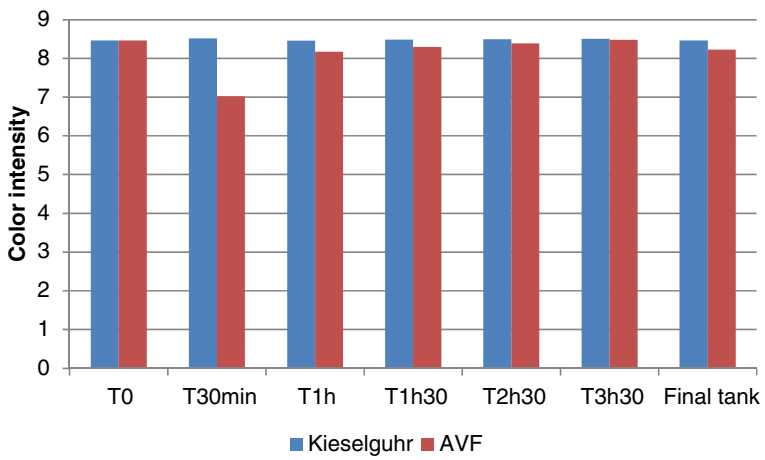

Figure 5. Color intensity on red wine during the filtration (trial 3015).

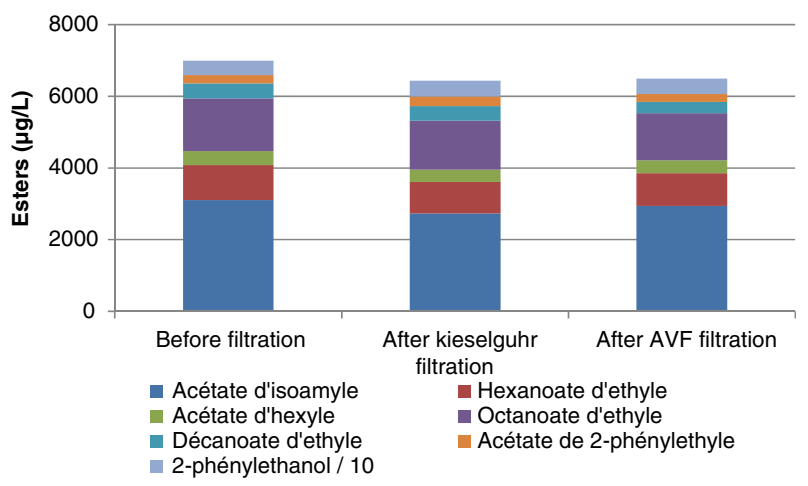

Figure 6. Esters analysis on white wine (trial 3013).

for the wine filtered by AVF is similar to the wine filtered by kieselguhr.

\subsection{Sensory analysis}

During the filtration a sensory difference between the wine filtered with kieselguhr and the wine filtered with AFV was detected in each trial. It seems that AVF gives paper flavor to the wine. We observed that this bad flavor disappear in time. The results of the triangular tests confirm that AVF doesn't impact the aroma or the taste of the wine after 2 weeks of the filtration (Table 8). All the triangular tests done on wines after 2 weeks of filtration are non significant, for all the six other trials. 
Table 6. Pesticides adsorbed in the AVF cake (trial 3017).

\begin{tabular}{|l|c|c|c|c|c|}
\hline Pesticides residues & $\begin{array}{l}\text { Initial } \\
\text { concentration in } \\
\text { unfiltered wine } \\
(\mu \mathrm{g} / \mathrm{L})\end{array}$ & $\begin{array}{l}\text { Initial quantity } \\
(\mu \mathrm{g} / \mathrm{g} \text { of AVF }) \\
(1)\end{array}$ & $\begin{array}{l}\text { Total quantity } \\
\text { adsorbed }^{\mathrm{b}} \\
(\mu \mathrm{g} / \mathrm{g} \text { of AVF })(2)\end{array}$ & Ratio (2)/(1) & $\begin{array}{l}\text { Total adsorbed } \\
\text { in the filter cake } \\
(\mu \mathrm{g} / \mathrm{g} \text { of AVF })\end{array}$ \\
\hline Azoxystrobine & 1.0 & 1.21 & 1.21 & 1 & 0.41 \\
\hline Boscalid & 7.6 & 8.85 & 8.03 & 0.90 & 2.75 \\
\hline Cyprodinil & 2.3 & 2.71 & 2.39 & 0.88 & 0.79 \\
\hline Dimetomorphe & 2.5 & 2.94 & 2.42 & 0.82 & 0.95 \\
\hline Fenhexamide & 32.6 & 37.88 & 15.82 & 0.41 & 8.16 \\
\hline Fludioxonil & 2.8 & 3.3 & 3.30 & 1 & 1.54 \\
\hline Fluopicolide & 4.7 & 5.48 & 3.44 & 0.62 & 1.66 \\
\hline Mandipropamid & 0.5 & 0.62 & 0.62 & 1 & 0.23 \\
\hline Pyrimethanil & 8.0 & 9.25 & 5.88 & 0.63 & 2.24 \\
\hline Myclobutanil & 0.6 & & & & 0.26 \\
\hline Benthiavalicarb & nd & & & & 0.02 \\
\hline Difenoconazole & nd & & & & \\
\hline Kresoxim-methyl & nd & & & & 0.01 \\
\hline Metrafenone & nd & & & & 0.04 \\
\hline Tebuconazole & nd & & & & 0.05 \\
\hline Trifloxystrobine & nd & & & & 0.02 \\
\hline Spiroxamine & nd & & & & 19.23 \\
\hline TOTAL & & 72.27 & & & \\
\hline
\end{tabular}

nd: Not detected (below the detection limit)

(a) By calculation: Concentration $(\mu \mathrm{g} / \mathrm{L}) *$ Total filtered wine / total of AVF.

(b) By calculation: Initial concentration $(\mu \mathrm{g} / \mathrm{L})$ - final concentration $(\mu \mathrm{g} / \mathrm{L}) *$ Total filtered wine/ total of PVF.

Table 7. Oenological parameters after filtration trials - difference between the wine filtered by kieselguhr and the wine filtered by AVF.

\begin{tabular}{|l|c|c|c|}
\hline & Red wines & White wines & Rosé wine \\
\hline Number of trials & 4 & 2 & 1 \\
\hline Color intensity & $-5.5 \%$ & $-17 \%(\mathrm{DO} 420)$ & $-21 \%(\mathrm{DO} 420)$ \\
\hline IPT & $-1.7 \%$ & $-2.1 \%$ & $-11.5 \%$ \\
\hline Delta E & +3.1 & +0.6 & +2.6 \\
\hline Isoamyle acetate & $-2.9 \%$ & $+2.8 \%$ & $-12 \%$ \\
\hline
\end{tabular}

Table 8. Triangular test results at different period after filtration (rosé wine 3019).

\begin{tabular}{|l|l|l|l|l|}
\hline & $\begin{array}{l}1 \text { day } \\
\text { after } \\
\text { filtration }\end{array}$ & $\begin{array}{l}1 \text { week } \\
\text { after } \\
\text { filtration }\end{array}$ & $\begin{array}{l}\text { 2 weeks } \\
\text { after } \\
\text { filtration }\end{array}$ & $\begin{array}{l}\text { 3 weeks } \\
\text { after } \\
\text { filtration }\end{array}$ \\
\hline Beginning of filtration & S & S & S & NS \\
\hline After 30 min filtration & S & S & NS & NS \\
\hline After 1h filtration & S & S & NS & NS \\
\hline After 2h filtration & NS & NS & NS & NS \\
\hline Final tank & S & S & NS & NS \\
\hline
\end{tabular}

S: Significant difference - NS: no significant difference.

\section{Conclusion}

The activated vegetal fibre (AVF) was evaluated at industrial scale in four different countries on red, white and rosé wines. The AVF was used as a substitute of kieselguhr in a precoat during a filtration. Pesticides content was quantified by HPLC/MS/MS on wine and on filter cake. The binding capacity of this fibre was demonstrate in each of the seven trials. The adsorption reached $65 \%$ in the AVF modality instead of a maximum of $7 \%$ in the kieselguhr modality. The reduction of the high adsorbed molecules was 55 to $88 \%$ with AVF on numerous molecules. Fenhexamide, Iprovalicarb and Metalaxyl-M are low absorbed molecules, with a reduction of 10 to $42 \%$ of their level. The pesticide level measured in the cake showed that all pesticides present in the wine where found in the cake. Some pesticides not detected in the wine were detected in the cake. These results confirm the high affinity of the AVF and suggest the potential use of AVF to prevent undesirable substances in wine.

Triangular tests done in comparison between the wine filtered by AVF and the wine filtered by kieselguhr showed a significant difference few days after filtration. No difference was found two weeks after the filtration. There is a small adsorption of color, but undetectable by the eyes.

Other filtration trials will be done on other matrices in order to accumulate more references on the activated vegetal fibre. Although the reduction of pesticides residues is technically feasible, it does not avoid the need for wine growers to have good practices at the vineyard.

\section{References}

[1] V. Lempereur, G. Geiger, C. Louaisil. WAC, 105-107 (2014)

[2] V. Lempereur, T. Sokolova, F. Davaux, R. Thomann. Bull. OIV, 85, 329-337 (2012)

[3] T. Philippe, N. Champeau, L. Barnavon, P. Cottereau, M. Grinbaum. Rev. des Oenol., 142, 27-1 (2012)

[4] A. I. Negueruela, J. F. Echavarri, F. Ayala, A. M. Lomas. Colorimetría en vinos. Zubía Monográfico, 7, 151-166 (1995) 